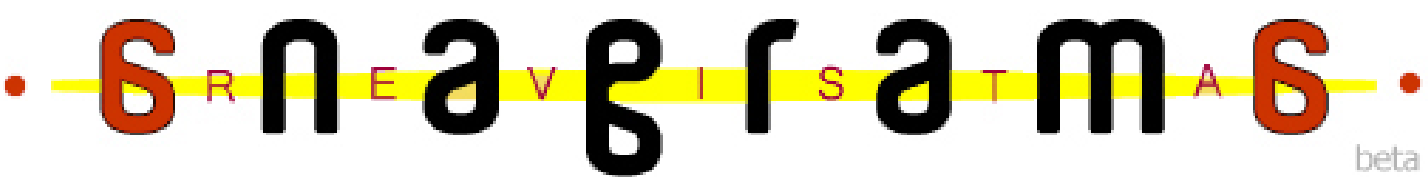

\section{A caracterização do discurso oral por meio de marcadores Conuersacionais}

\section{Marília de Toledo Kodic ${ }^{1}$}

\section{Resumo}

Partindo da análise de áudio e transcrição do discurso proferido por um falante culto da cidade de São Paulo, o presente artigo tem como objetivo verificar elementos conhecidos na Análise Conversacional como Marcadores Conversacionais. O estudo procura identificar e definir as unidades de conversação encontradas no corpus e demonstrar que, para uma interação oral, são necessários princípios comunicativos em detrimento de princípios meramente sintáticos. É discutido também o papel dos marcadores segundo diversos autores, focalizando nas funções interacional e textual.

Palauras-chave: análise do discurso oral, função interacional, função textual, marcador conversacional

Tanto na produção oral como na escrita o sistema lingüístico é o mesmo para a construção das frases, mas as regras de sua efetivação, bem como os meios empregados são diversos e específicos, o que acaba por evidenciar produtos lingüísticos diferenciados. (RATH, 1979: 20)

\section{Considerações Iniciais e Conceituação}

Como base para as considerações do artigo foi utilizada a alocução de uma mulher de aproximadamente trinta anos, paulistana, professora de História do Ensino Fundamental. A gravação de aproximadamente trinta minutos tem como objeto uma aula datada de nove de dezembro de 1976, cujo tema é a periodização da História, e foi transcrita para fins observacionais. O texto evidencia que os elementos de caráter cognitivo-informativo são permeados por outros que ficam à margem do assunto, desnecessários para o entendimento do contexto: os denominados Marcadores Conversacionais (MC).

${ }^{1}$ Graduanda em Letras pela Faculdade de Filosofia, Letras e Ciências Humanas da USP e em Jornalismo pela Faculdade Cásper Líbero. 
Segundo Émile Benveniste (1976), a enunciação é a atividade lingüística daquele que fala no momento que fala, de tal modo que é possível identificar em cada enunciado pistas ou marcas lingüísticas que evidenciem o sujeito. Por marcador conversacional entende-se uma expressão que serve de elo de ligação entre unidades comunicativas e que torna a linguagem falada dinâmica e expressiva.

Constituem sinais que amarram o texto enquanto estrutura de interação interpessoal e asseguram o desenvolvimento continuado do diálogo, freqüentemente operando como dêiticos discursivos que pontuam o texto conversacional. São em sua maioria desprovidos de conteúdo semântico e papel sintático, e irrelevantes na interpretação do tópico; contudo, não deixam de ser imprescindíveis e recorrentes na construção do discurso.

Além dos verbais, há também os componentes supra-segmentais ou prosódicos (pausa, entonação, etc), que são de natureza lingüística mas não de caráter verbal; e os nãoverbais ou paralingüísticos (olhar, riso, gesticulação, etc), que não podem ser verificados no corpus.

Pelo fato de não se enquadrarem nos critérios de classificação das dez classes de palavras propostas pela NGB (Nomenclatura Gramatical Brasileira), ocorre uma ausência de consenso terminológico a respeito dos marcadores em questão. Acerca desse mesmo mecanismo é possível encontrar diversas denominações, como: apoios do discurso, expressões de situação, marcadores de estruturação da conversa, operadores discursivos, palavras denotativas, entre outros.

\section{Identificação e classificação dos mCs no corpus}

Quanto à forma, os MCs se apresentam como elementos simples, compostos ou oracionais, podendo aparecer combinados. Os simples contêm um só item lexical, como: bem... (linha 9), exatamente... (linha 44) e hein... (linha 134). Os compostos, ou complexos, apresentam um caráter sintagmático e aparecem em: bem então (linha 6), quer dizer (linha 39) e veja bem (linha 134). Os oracionais correspondem a pequenas orações que se apresentam nos diversos tempos e formas verbais: eu digo assim (linha 7) e se a gente for pensar... (linha 108). Como exemplo de combinação, temos: então veja bem (linha 30), que é ao mesmo tempo composto e oracional; e então vamos dizer o seguinte... (linha 148), idem. 
Quanto à posição, os marcadores podem ser iniciais, mediais ou finais. Os iniciais, ou pré-posicionados, são os que caracterizam o início ou a tomada do discurso: então (linha 1) e é:: (linha 153). Os mediais podem ser de sustentação, e servem para manter o turno ou assegurar a atenção do ouvinte, o que ocorre repetidas vezes no texto em questão: okay? (linha 129), tá? (linha 180) e né? (linha 185). Há também os mediais de não sustentação, que não têm a preocupação de manter o turno: assim... (linha 45), agora... (linha 92) e quer dizer... (linha 56). Os marcadores finais indicam o término de um turno, constituindo, portanto, um lugar relevante para a transição - o chamado LRT -, que nada mais é do que um determinado ponto no qual a fala é considerada possivelmente completa: certo? (linha 4), entendeu? (linha 69), e compreende? (linha 111).

Os marcadores mais recorrentes no texto, em relação à posição, são mediais de sustentação: certo? (46 repetições) e entende? (30 repetições). Estes poderiam ser classificados como finais; porém, como não há uma troca constante de turnos, sua função principal consiste em certificar a atenção dos ouvintes.

Quanto ao aspecto semântico, há os elementos prosódicos, como os de pausa éh:: ah:: (linha 66) e os de entonação DEPOIS... (linha 78). Há expressões que continuam semanticamente válidas, mas a informação que passam não colabora para o conteúdo referencial do texto como estrutura tópica: você vai ver que... (linha 16), então a gente vai observar... (linha 81) e então agora nós vamos fazer o seguinte... (linhas 137-138).

Há marcadores que funcionam como sinais de armação do quadro tópico, ou framing (KELLER, 1979: 158). Indicam o panorama em que se encontra a conversação: agora a gente... tem aqui... (linhas 102-103), a primeira coisa que a gente vai... observar... (linhas 136-137) e então vamos ver agora... (linha 205). São encontrados também os sinais de assentimento: hum hum (linha 159) e de discordância: não... (linha 150); que não tem apenas função fática.

Marcadores de caráter parentético configuram um breve desvio, digressão, aparte ou parêntese, relativamente ao tópico em desenvolvimento. Um exemplo é o advérbio exatamente (linha 44). Indagações propostas são marcadores que constituem uma espécie de pergunta retórica, para a qual não se espera resposta: vai predominar o quê? (linha 33), só um minuto sim? (linha 66) e lembra disso? (linha 173); em que o locutor mal faz a pergunta e já a responde, sem que os ouvintes tenham tempo de responder.

No aspecto sintático, devemos levar em conta os marcadores verbais lexicalizados ou não, cujas emissões são completas por si e autônomas entonacionalmente, 
caracterizando total independência sintática. É o caso dos marcadores do tipo certo? (linha 4), éh (linha 28) ah:: (linha 99) e né? (linha 132). Os não lexicalizados, como ahn:: (linha 49), hein... (linha 134) e hum hum (linha 159), entremeiam a estrutura oracional sem integrá-la sintaticamente.

Existe, ainda, um grupo de elementos que:

mantém, em menor ou maior grau, parcela do seu sentido. Com efeito, eles mantêm parcialmente o sentido e a função sintática originais, assumindo, por acréscimo, uma função pragmática ${ }^{2}$ (URBANO, 2003: 101).

Tomemos como exemplo a palavra assim (linha 77). Ela liga-se sintaticamente a "bem rudimentar" e sinaliza, ao mesmo tempo, a hesitação do falante, apontada também pelo alongamento e repetição da palavra "bem": "um modo assim bem:::: bem rudimentar... bem:::... bem tosco mesmo...”.

Visto unicamente sob o aspecto pragmático, assim preenche uma pausa referente a incerteza, e caso o vocábulo não tivesse sido empregado, a pausa se converteria em um silêncio. Como preenchimento de pausa, assim pode ser considerado como uma ruptura de informação, proporcionando momentos facilitadores para a premeditação e o preparo do texto e oferecendo tempo para o falante se situar. A palavra assim assume então, além de classe de "advérbio de frase", a de "advérbio de enunciação": "não servem para tornar mais explícitas as 'pequenas cenas' mas veiculam opiniões, atitudes que o locutor assume a respeito do fato de falas delas" (ILARI \& GERALDI, 1985: 39).

A maior parte dos Marcadores Conversacionais encontrados no texto expõe a necessidade de apoio para a progressão conversacional, ou a busca de aprovação discursiva. É o caso dos marcadores mencionados acima como mediais de sustentação, notadamente o certo? e o entende?, que juntos aparecem 76 vezes em um discurso de aproximadamente meia hora.

Tal recorrência justifica-se no fato de que o interlocutor está dando uma aula a alunos do Ensino Médio; logo, a atenção dos mesmos está sujeita a ser facilmente perdida pela distração característica da faixa etária e da própria situação de sala de aula. Assim, a professora de História estará sempre buscando alertar e exigir a atenção e compreensão de seus alunos.

\footnotetext{
2 Por "pragmático", entende-se "a relação entre a linguagem e seus usuários".
} 
Outro tipo de marcador bastante freqüente no texto refere-se a momentos de hesitação. Sozinhos ou em coocorrência, os marcadores de pausa sinalizam a intenção do falante em manter o turno e a atenção dos ouvintes enquanto planeja a seqüência. As paradas são encontradas sob forma de alongamentos: ah:::: (linha32), que:::: (linha 148) e éh:::: (linha 175); pausas longas: aqui...... (linha 107) e bem...... (linha 195); repetições: Onde... ONde foi (linha 47) e ::... um SIMples... um SIMples pedaço (linha 50) e cortes de palavras ou de entonação, interrupções sintáticos ou semântico-sintáticas: exist/ em/ entende?... es/ ... (linha 40), a gen/... o cérebro... (linha 58), eles cort/ éh lascavam... (linha 89) e então ES/ éh:: (linha 177).

As constantes hesitações dão-se pelo fato de que ao dar a aula, a professora de História, provavelmente, recorre apenas à sua memória para citar e explicar os fatos aos seus alunos. Logicamente, ao contrario do que aconteceria se a professora estivesse simplesmente lendo um livro didático aos seus alunos, a memória apresenta falhas e a fala é naturalmente mais confusa do que a escrita.

\section{Funções Textuais e Interpessoais}

Podemos observar diferentes categorizações para diferentes autores em relação aos MCs. Fraser (1999: 931-952) nota duas classes principais de MCs: os que relacionam mensagens - ou seja, aqueles que relacionam algum aspecto das mensagens veiculadas pelos segmentos que seguem e precedem o marcador - e os que relacionam tópicos - ou seja, aqueles que envolvem algum aspecto da condução discursiva.

Para Castilho, (1989: 273-4) eles comportam dois cargos específicos: o interpessoal (ou pragmático, segundo Marchuschi), em que o marcador serve para administrar os turnos conversacionais; e o textual, em que os falantes acionam os marcadores para negociação e desenvolvimento do tema.

Essa classificação funde-se com a de Risso (1996: 423), que atesta que a natureza da ação discursiva dos MCs permite que estes se distribuam entre dois planos: na estrutura textual, com a organização da informação, ou na estrutura interpessoal, com a organização das relações entre os interlocutores. Os MCs atuam no plano da enunciação textualinterativa com funções tanto de projetar relações interpessoais (quando o foco funcional 
não está no seqüenciamento de partes do texto) quanto destacar a articulação textual (quando a prevalecente não se encontra mais no eixo da interação).

Os conceitos de Dik (1997: 384) de Constituintes Extra-Oracionais (CEOs) constituem, assim como os MCs, expressões que não podem ser facilmente descritas em termos de regras e normas intra-oracionais e que podem tanto estar sozinhas como preceder, seguir ou interromper uma oração. São eles:

a. controle ou monitoramento da interação: pertencem à criação e manutenção das condições interacionais que devem ser preenchidas para que um evento discursivo seja implementado.

b. especificação de atitude: pertencentes ao tom emocional e de atitude dos interlocutores em relação ao discurso

c. organização do discurso: pertencem à organização, estruturação e apresentação do conteúdo oracional.

d. execução do discurso: desempenham uma função na expressão do conteúdo real do discurso.

Assim, pode-se fazer uma analogia entre os CEOs e as classificações de Castilho, Risso e Marchuschi para os MCs, dado que é possível apontar uma similaridade entre $a$. e $b$. e a função interpessoal ou pragmática; e entre $c$. e $d$. e a função textual.

Os MCs que desempenham funções interpessoais cumprem alguma função advinda diretamente da relação tête-à-tête entre os interlocutores, integrando o componente interacional da linguagem.

Os MCs que desempenham funções textuais operam num nível hierarquicamente superior ao da sentença e funcionam como mecanismos de coesão textual, estabelecendo um tipo de relação semântica e estrutural entre diferentes unidades discursivas. Assim, podem propiciar abertura, expansão, retomada e fechamento de tópicos e distinção de estruturas de figura e fundo.

Os MCs apresentam fortes tendências para cumprir concomitantemente as duas funções. Essa simultaneidade pode se dar: com predominância de uma das funções, que é a situação mais freqüente; com expressão forte das duas funções; ou com uso fracamente expressivo de ambas as funções. Estamos tratando, no entanto, de funções gerais, em cujos domínios uma ampla variedade de subgrupos pode ser apontada. 


\section{Considerações finais}

A abordagem aqui apresentada não pretende ser completa, mas procura elaborar e entender elementos cruciais para uma visão detalhada acerca das especificidades da fala e para a medida de sua naturalidade. É preciso que a linguagem seja vista como artifício de interação, de correlação e de construção de identidades.

A fim de suscitar e manter uma conversação, temos como preceito que os interlocutores devem partilhar de noções comuns. São estas a competência lingüística, a envoltura cultural e o domínio das situações sociais de informação; relacionados à progressão do texto oral, através do uso de marcadores que contribuem para tal, observando a conversação como um meio de aquisição de uma finalidade interacional a ser atingida pelos interlocutores.

A partir da análise feita, é possível perceber a importância dos marcadores para a espontaneidade e continuidade de uma conversação, tornando-a dinâmica e eficaz. Os MCs ainda proporcionam um campo de pesquisa vasto e promissor, sobretudo se atentarmos para a necessidade de um enquadramento mais preciso no contexto da Gramática Funcional.

\section{Referências Bibliográficas}

BENVENISTE, Émile. Problemas de lingüística geral. Vol. I, São Paulo: Cultrix, 1976.

CASTILHO, Ataliba Teixeira. "Para o estudo das unidades discursivas". In. Português culto falado no Brasil. Campinas: Editora da Unicamp, 1989.

CHAGAS, Carmem Helena das. "O texto oral dialogado: a importância dos marcadores conversacionais”. Revista Philologus, Rio de Janeiro, ano 13 no. 37, 2007.

DIK, Simon. The theory of functional grammar. Part 2: Complex and derived constructions. NewYork: Mouton de Gruyter, 1997. 
FRASER, Bruce. "What are discourse markers?” In. Journal of Pragmmatics. v.31, 1999, p.931- 952 .

ILARI, Rodolfo e GERALDI, João Wanderley. Semântica. São Paulo: Ática, 1985.

LE PAGE, Robert. \& TABOURET-KELLER, Andre. Acts of identity: creole-based approaches to languages and ethnicity. Cambridge: Cambridge University Press, 1985.

MARCUSCHI, Luiz Antônio. "Marcadores Conversacionais". In Análise da Conversação. São Paulo: Ática, 1997.

PENHAVEL, Eduardo. "Sobre as funções dos Marcadores Discursivos". Revista Estudos Lingüísticos, São Paulo, no. XXXIV/ 2005, pp. 1296-1301.

PRETI, Dino e URBANO, Hudinilson (org.). A linguagem falada culta na cidade de São Paulo. São Paulo: T.A.Queiroz/ FAPESP, 1990.

RATH, Rainer. Kommunikationspraxis: Analysen zur Textbildung u. Textgliederung im gesprochenen Deutsch. Göttingen: Vandenhoeck und Ruprecht, 1979

URBANO, Hudinilson. "Marcadores Conversacionais". In PRETI, Dino (org). Análise de Textos Orais. São Paulo: Humanitas Publicações FFLCH/ USP, 2003. 